\title{
IRTIIE
}

\section{DETERMINING THE INFLUENCE OF THE FOCAL LENGTH ON THE COEFFICIENT OF PERFORMANCE IN OBTAINING THE DIMENSIONAL CHARACTERISTICS BY PHOTOGRAMMETRIC METHOD}

\author{
Georgi Georgiev \\ Faculty of Technics and Techology of Yambol, Trakia University of Stara Zagora \\ Graf Ignatiev 38, 8600 Yambol, Bulgaria \\ mobile: +359887185869, e-mail: georgi.georgiev@trakia-uni.bg
}

\begin{abstract}
The use of photogrammetric method for determining the geometric parameters of objects of engineering practice is still limited due to a number of factors. One of them comes from the nature of the process capturing and defining the regime elements.

For the rapid determination of the dimensions of the digital model should be calculated coefficient of performance, taking into account the impact of various factors. This article discussed the influence of the focal length on the coefficient of performance.
\end{abstract}

Keywords: photogrammetry, non-contact measurement, photography, measurement accuracy.

\section{INTRODUCTION}

Photogrammetry is a method which is based on the triangulation [6], known of the humanity from the ages. Despite its wide application in many fields of scientific knowledge is still limited application in the field of controlling the dimensions of the machine details [1, 4]. In some literature references developments for specific cases of application can be found, but this research has not found a systematic approach for describing the method of measuring geometric characteristics of small objects. Independently of technique used to obtain the original digital information for the physical object - 3D scanners, lasers, optical cameras or cameras, photogrammetry involves several steps (Figure 1).

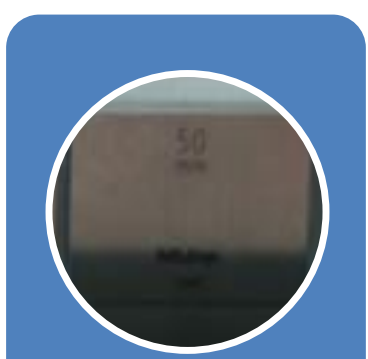

Calibration

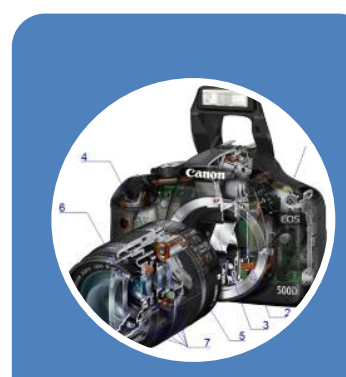

Shooting

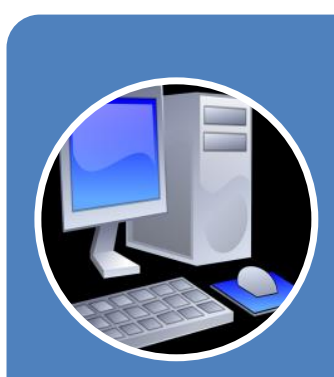

Processing of digital information

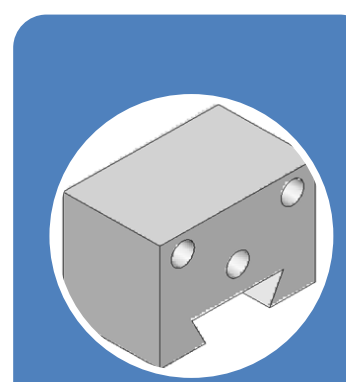

Obtaining geometric characteristics
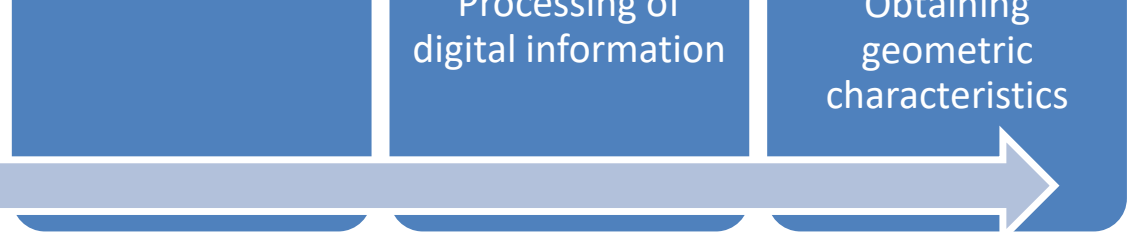

Figure 1. Sequence of photogrammetric method for measuring geometric characteristics of small objects

IRITIE Vol. 4, No. 4, 2016 ISSN 1314-8788 (print), ISSN 1314-8796 (online), doi: 10.15547/artte.2016.04.005 


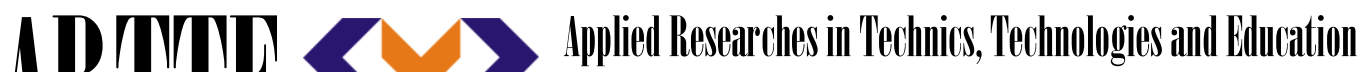 Journal of the Faculty of Technics and Technologies, Trakia University https://sites.google.com/a/trakia-uni.bg/artte/}

Since the method is based on the principle of perspective [3] it is necessary to accurately calculate the coefficient of performance, with which the image is scaled by the shooting technique compared with the actual physical object.

If carried out measurements by a single image to calculate the coefficient of transformation it is necessary to the shooting subject, in the same plane, should be shot object with known geometrical features such as flat parallel gauge block.

If it is necessary to perform the measurement of multiple photos above mentioned condition would occur very difficult. It would be required in advance to make shoots of the reference under the same conditions with that will be done shooting of the object. Then summarized coefficient of performance which is valid for all photos are determined. Accurate determination of the coefficient of transformation will allow for easier and more accurate determination of the shape and size of the objects by reverse engineering $[7,8]$.

On this factor affects many diverse factors that are caused by the technical characteristics of the shooting technique, from shooting conditions, regime factors such as the size of the object, distance between the subject and the shooting technique, focal length, lighting and other. Each factor has a certain influence, which should be examined to ensure the most accurate value of the coefficient.

\section{THEORETICAL TREATMENT}

On the magnitude of the coefficient of performance influencing a number of factors that need to be investigated experimentally:

$$
\mathrm{K}_{\mathrm{T}}=f\left(K_{L}, K_{f}, \mathrm{~K}_{\text {осв. }} \ldots \ldots K_{n}\right)
$$

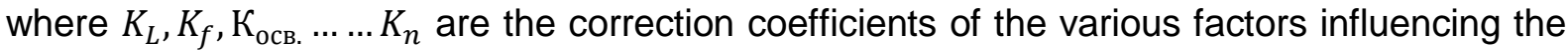
formation of $K_{T}$ - distance $L$, focal length $f$, lighting, the size of the matrix, used software for photo editing and reading dimensional, quality of the surface of the subject, resolution of the monitor, etc. [3].

In the present article will be examined the impact of focal length on the coefficient of performance.

According to the formula:

$$
\mathrm{Y} 1=\mathrm{Y} 2 / \mathrm{KT}
$$

the received size $\mathrm{Y} 1$ depends on the number of accounted pixels of the image $\mathrm{Y} 2$ and the coefficient of performance $\mathrm{K}_{\mathrm{T}}$. Moreover, the focal length is maintained constant. In order to investigate also its influence the formula gets type:

$$
Y_{1}=\frac{Y_{2}}{K_{L}} \cdot K_{f}
$$

where $\mathrm{K}_{\mathrm{f}}$ is a correction coefficient which serves for aligning the current focal length toward the focal length in case of which is defined $K_{L}(f=55 \mathrm{~mm})$.

\section{EXPERIMENTAL PART}

For conducting planned experiment has been used an unit, shown in Figure 2, a camera "Canon" and a standard lens with range of focal lengths from 18 to $55 \mathrm{~mm}$. A gauge block 25 is shooting while maintaining a constant distance $L=270 \mathrm{~mm}$ in the range of focal lengths 


\section{IR'I'TE}

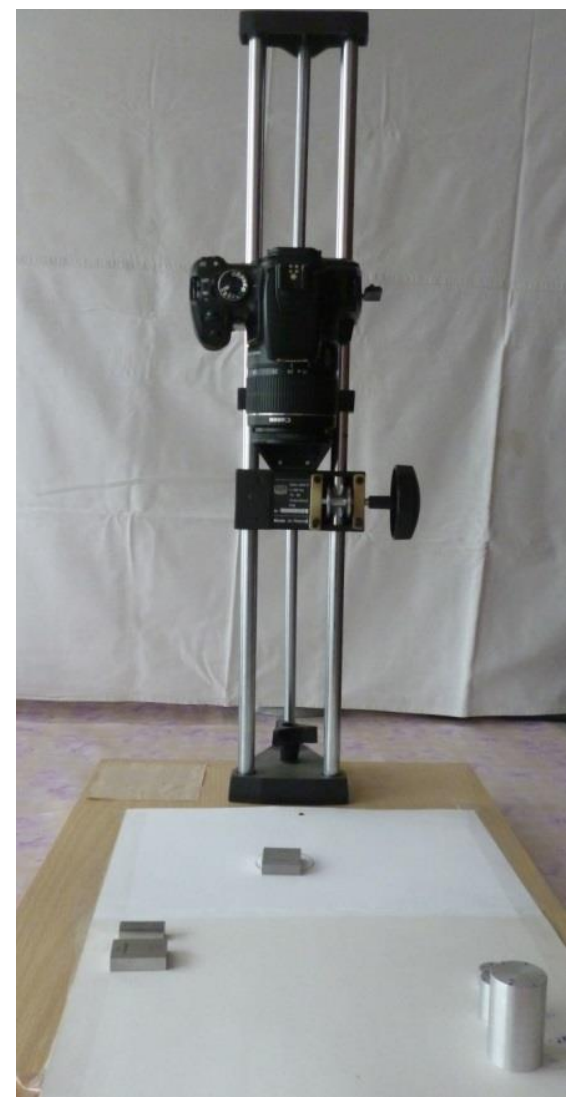

Figure 2. Unit for experimental capturing of the calibers and details

Ipplied Researrohes in Technics, Technologies ind Bductition

Journal of the Faculty of Technics and Technologies, Trakia University https://sites.google.com/a/trakia-uni.bg/artte/

provided by the lens. The obtained results are given in Table 1 and processed for obtaining dependence with the software "Excel" from the Microsoft Office package.

For theoretical determination of the coefficient for impact of focal length are studied two equations: linear and exponential with aim smoothing the experimental data from Table 1. The identification of the mathematical model based on experimental data is made with program „Korelia“ [9]. The program offers a user-friendly interface, conditioned by the presence of language to describe the experimental data and recognition module for research process. Bidirectional data transfer is possible, as supported file formats such as CSV, XLS, XML and Paradox. Identified models can be analyzed and compared on a number of parameters and thus be selected most appropriate for a particular data set.

Program "Korelia" allows graphic visualization of data and results, as well as processing of graphic representation. The equations have type:

$$
\begin{gathered}
y=13,7842 \cdot x+3,604, R^{2}=0,997 \\
y=5963 \cdot\left[1-e^{\left(\frac{-x}{392,73}\right)}\right]-18,181, R^{2}=0,996
\end{gathered}
$$

As required by the criteria of Occam [4] equation (4) is selected. Figure 3 presents the results of measurements and selected depending. The calculated results for $K_{f}^{T}$ by the equation (4) are given in Table 2 and they are compared with values obtained for the coefficient of experimental data $K_{f}^{\mathrm{E}}$. Mean and mean square errors are calculated.

Table 1. Measurement results of gauge block 25 at a range of change of focal length

\begin{tabular}{|c|c|c|c|c|c|c|c|}
\hline 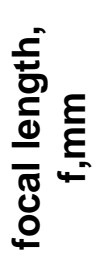 & 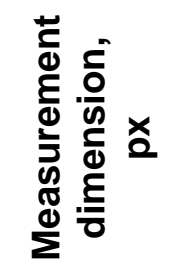 & 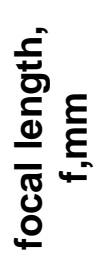 & 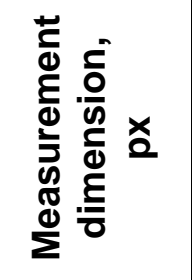 & 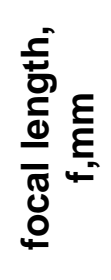 & 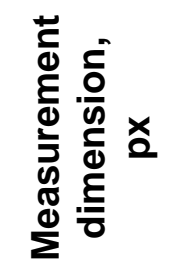 & 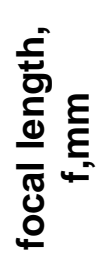 & 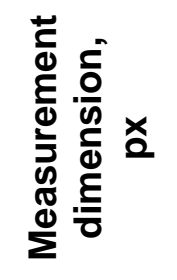 \\
\hline 18 & 264,32 & 32 & 441,3672 & 41 & 564,5104 & 48 & 660,6815 \\
\hline 20 & 277,6459 & 33 & 456,3551 & 42 & 586,3736 & 49 & 684,6576 \\
\hline 21 & 306,2352 & 35 & 477,3353 & 43 & 594,4847 & 50 & 705,9081 \\
\hline 24 & 331,2188 & 36 & 498,578 & 44 & 606,7421 & 51 & 722,5047 \\
\hline 27 & 365,8094 & 37 & 519,5611 & 45 & 618,7277 & 53 & 734,6062 \\
\hline 28 & 379,3031 & 39 & 544,4067 & 46 & 630,7139 & 55 & 753,5926 \\
\hline 30 & 423,2659 & 40 & 554,4341 & 47 & 648,6941 & & \\
\hline
\end{tabular}
$\mathrm{f}=18 \div 55 \mathrm{~mm}$

IRTIIE Vol. 4, No. 4, 2016 ISSN 1314-8788 (print), ISSN 1314-8796 (online), doi: 10.15547/artte.2016.04.005 


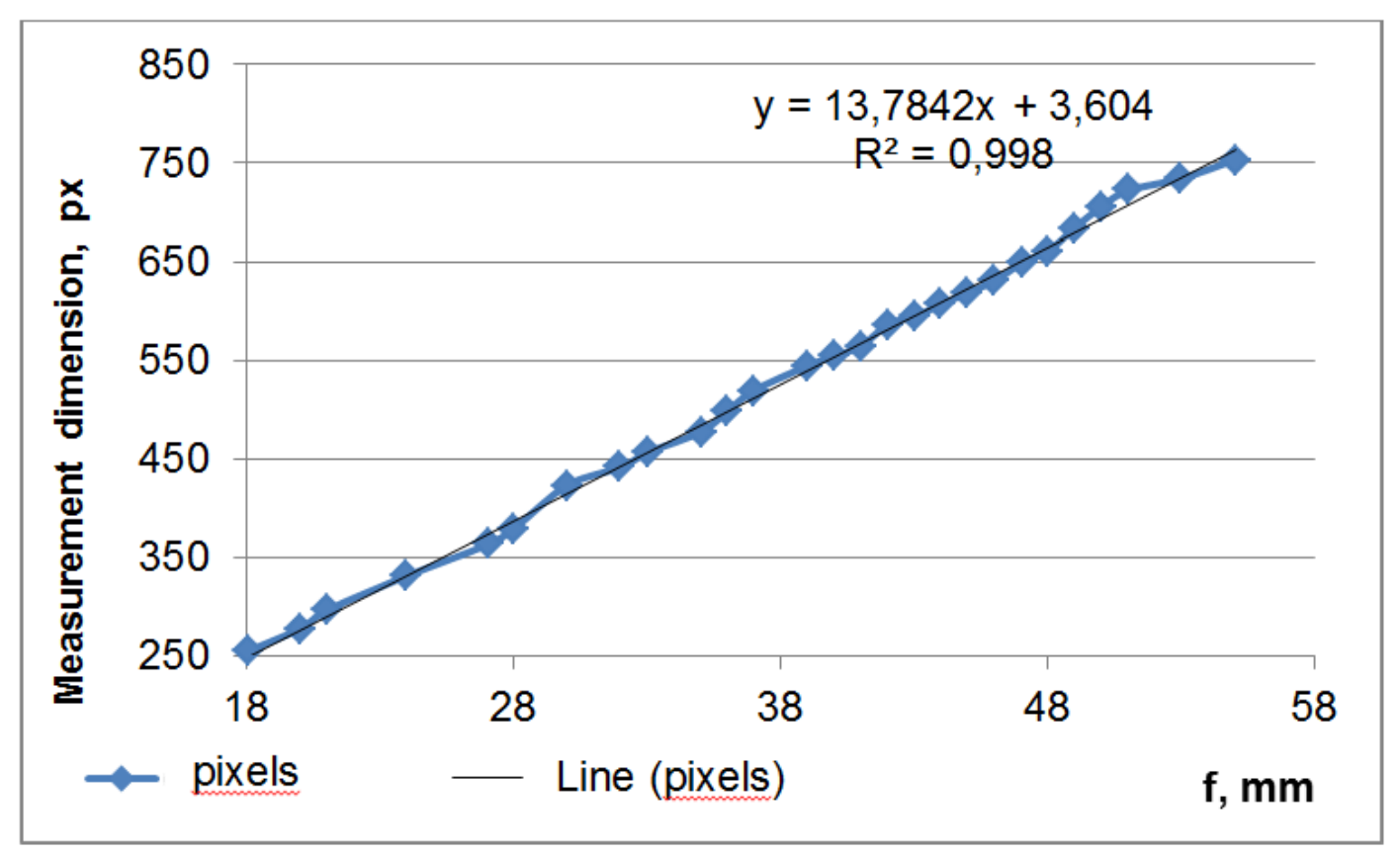

Figure 3.

Depending on the measurement dimensions from changing of the focal length

Table 2. Comparison of experimental and theoretical coefficients reflecting the impact of focal length

\begin{tabular}{|c|r|r|r|c|c|r|r|}
\hline $\begin{array}{c}\text { Focal } \\
\text { length, } \\
\mathbf{m m}\end{array}$ & \multicolumn{1}{c|}{$\boldsymbol{K}_{\boldsymbol{f}}^{\mathrm{E}}$} & \multicolumn{1}{c|}{$\boldsymbol{K}_{\boldsymbol{f}}^{\boldsymbol{T}}$} & $\begin{array}{c}\text { Error, } \\
\%\end{array}$ & $\begin{array}{c}\text { Focal } \\
\text { length, } \\
\mathbf{m m}\end{array}$ & \multicolumn{1}{c|}{$\boldsymbol{K}_{\boldsymbol{f}}^{\mathrm{E}}$} & \multicolumn{1}{c|}{$\boldsymbol{K}_{\boldsymbol{f}}^{\boldsymbol{T}}$} & \multicolumn{1}{c|}{$\begin{array}{c}\text { Error, } \\
\%\end{array}$} \\
\hline 18 & 2.851 & 3.068 & 0.419 & 41 & 1.335 & 1.342 & 0.07 \\
\hline 20 & 2.714 & 2.76 & 0.357 & 42 & 1.285 & 1.31 & 0.063 \\
\hline 21 & 2.461 & 2.628 & 0.33 & 43 & 1.268 & 1.28 & 0.057 \\
\hline 24 & 2.275 & 2.2978 & 0.263 & 44 & 1.242 & 1.251 & 0.051 \\
\hline 27 & 2.077 & 2.041 & 0.211 & 45 & 1.218 & 1.227 & 0.045 \\
\hline 28 & 1.987 & 1.968 & 0.197 & 46 & 1.195 & 1.196 & 0.04 \\
\hline 30 & 1.78 & 1.836 & 0.17 & 47 & 1.162 & 1.171 & 0.035 \\
\hline 32 & 1.707 & 1.721 & 0.147 & 48 & 1.141 & 1.146 & 0.03 \\
\hline 33 & 1.651 & 1.669 & 0.136 & 49 & 1.101 & 1.123 & 0.025 \\
\hline 35 & 1.579 & 1.573 & 0.116 & 50 & 1.068 & 1.1 & 0.02 \\
\hline 36 & 1.511 & 1.529 & 0.108 & 51 & 1.043 & 1.079 & 0.016 \\
\hline 37 & 1.45 & 1.488 & 0.099 & 53 & 1.026 & 1.038 & 0.008 \\
\hline 39 & 1.384 & 1.411 & 0.084 & 55 & 1 & 1 & 0 \\
\hline 40 & 1.359 & 1.376 & 0.076 & \multicolumn{3}{c}{ Mean error, \% } & 0.13664732 \\
\hline & & & & \multicolumn{3}{c}{ Mean square error, \% } & 0.02945705 \\
\hline
\end{tabular}

IRTTIE Vol. 4, No. 4, 2016 ISSN 1314-8788 (print), ISSN 1314-8796 (online), doi: 10.15547/artte.2016.04.005 


\section{IRTITE}

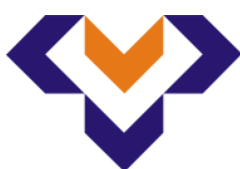

Ipplied Reseitrones in Teednicis, Technologies and Eductation

Journal of the Faculty of Technics and Technologies, Trakia University https://sites.google.com/a/trakia-uni.bg/artte/

In the experiment is found that the regulation of focal length cannot ensure with high accuracy and this due to the design of the camera what is adopted. This can be established by comparing the set focal length during shooting and reading of the characteristics of the image which is visible in the menu "Properties" of the file.

However, when comparing the theoretical model for determining $K_{f}$ and experimental data is found that the average percentage error is about $0.1 \%$, finding giving rise to acceptance of the theoretical model.

\section{EXPERIMENTAL VALIDATION OF THE MODEL FOR DETERMINING COEFFICIENTS REPORTING CHANGE OF THE FOCAL LENGTH $K_{f}$}

To confirm operability of the currently displayed equation the check has been made in which as an object of measurement is used detail with reference dimension $\varnothing 15,139 \mathrm{~mm}$. On setting presented in Figure 1 with the same camera, the detail is photographed in various focal lengths and constant distance between the subject and the matrix of the camera $L=$ $250 \mathrm{~mm}$.

The changes of the Measurement object and the distance $L$ is driven by it, to obtain greater filling of the matrix, respectively, a larger number of counted pixels.

The results are presented in Table 3 . The reported pixels for the size measurement are compared to the calculated by the accepted theory distribution of $K_{f}$ by the formula (4). The error and the error rate are calculated for each measurement, the latter is represented graphically in Figure 4.

Table 3. The results from the experiment for confirming efficiency of the theoretical factor considering the impact of focal length

\begin{tabular}{|c|c|c|c|c|}
\hline $\begin{array}{c}\text { focal length, } \\
\mathbf{f}[\mathbf{m m}]\end{array}$ & $\begin{array}{c}\text { Reading pixels, } \\
\text { px }\end{array}$ & $\begin{array}{c}\text { Estimated number of } \\
\text { pixels by formula (1.2), } \\
\text { px }\end{array}$ & Error, px & $\begin{array}{c}\text { Percentage } \\
\text { error, \% }\end{array}$ \\
\hline 18 & 252.451 & 251.993 & 0.458 & 0.182 \\
\hline 25 & 349.173 & 348.376 & 0.797 & 0.229 \\
\hline 33 & 459.168 & 458.528 & 0.640 & 0.140 \\
\hline 39 & 541.736 & 541.142 & 0.594 & 0.110 \\
\hline 43 & 595.868 & 596.218 & 0.350 & 0.059 \\
\hline 47 & 651.482 & 651.294 & 0.188 & 0.029 \\
\hline 53 & 733.656 & 733.908 & 0.252 & 0.034 \\
\hline 55 & 761.555 & 761.446 & 0.109 & 0.014 \\
\hline
\end{tabular}

From Figure 4 can be found that by increasing the focal length error between the received data for the size in pixels by the theoretical dependence and experimental research in the range greatly reduces and the trend of dependence tends to zero. These conclusions are derived and in the attempts to determine the impact of $\mathrm{K}_{\mathrm{L}}$, where measurements are conducted with different focal lengths. It is necessary to conduct additional studies to identify opportunities for more precise defining and controlling the focal length in order to refining the results and reducing the received error in measurements. 


\section{ARTTIE $Y$}

Ipplied Reseitrones in Teednicis, Technologies and Eductation Journal of the Faculty of Technics and Technologies, Trakia University https:///sites.google.com/a/trakia-uni.bg/artte/

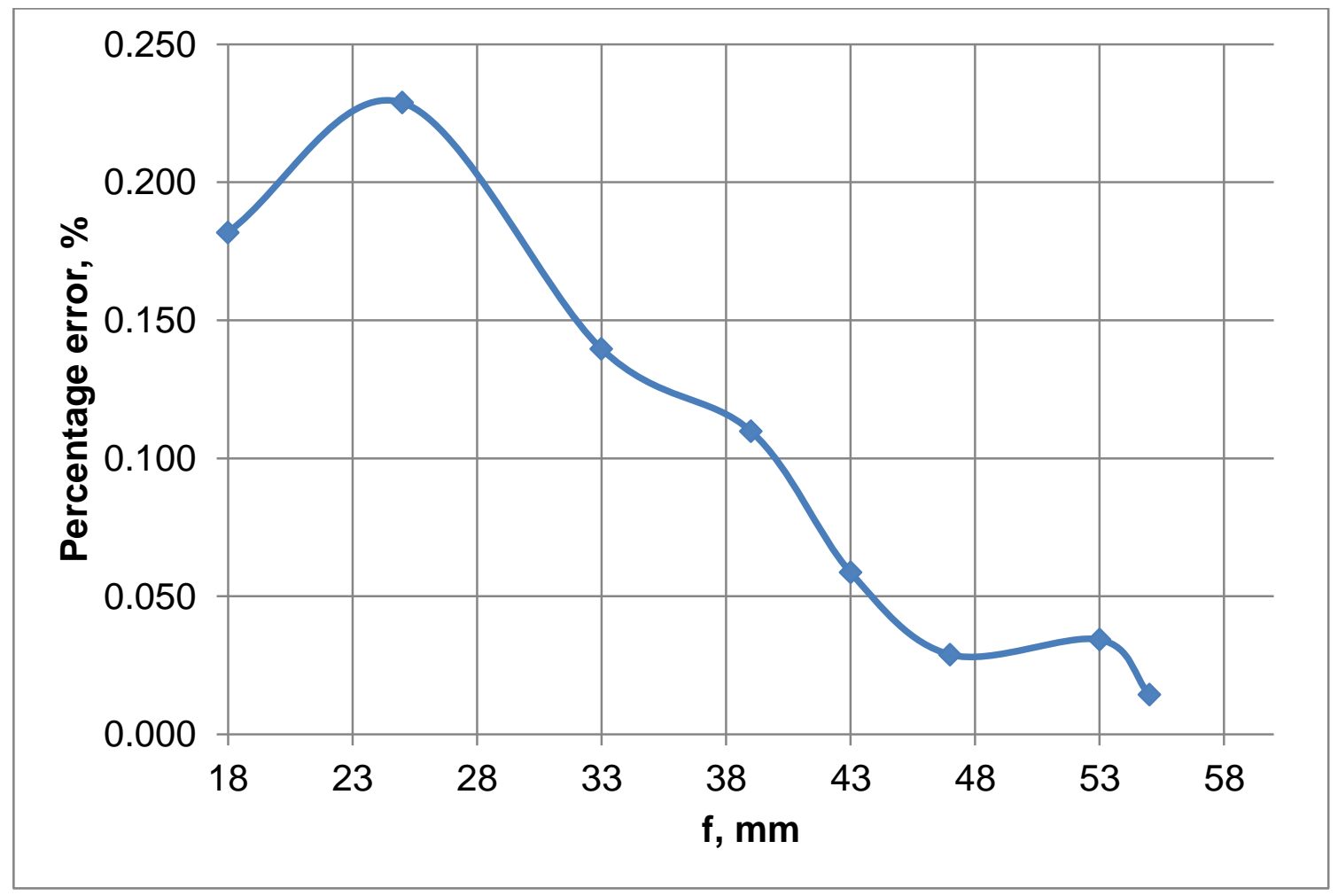

Figure 4.

Percentage error between experimental data and calculated by formula (4) values for Kf

\section{CONCLUSIONS}

As a conclusion from the survey can be formulated following conclusions:

- Accuracy of reading the dimensions of captured objects depends significantly on the accuracy with which is determined the coefficient of transformation $\mathrm{K}_{\mathrm{T}}$ as the value it most highly influenced by distance $L$ from shooting subject to the matrix of the camera and focal length $f$, in which their impact are mixed.

- The location of objects relative to the matrix of the camera does not have a significant impact on the accuracy of the obtained dimension.

- It has been found that the dependence of the coefficient of performance of the focal length is a linear function.

- The displayed depending about the coefficient of transformation, depending on the focal length $f$, allows for its determination, with sufficient precision in space research, allowing consideration of the dimensions of objects with high accuracy.

\section{REFERENCES}

[1] Atanasov A., B. Sakakushev. Opportunities for the application of photogrammetric method for measuring the macro and microgeometry in engineering. Magazine. "Proceedings of the Union of Scientists - Rousse", 1/2012, series "Technical Sciences" № 5, 2012, issue 5, pp. 21-24, ISSN 1311-106X.

[2] Georgiev Georgi, Boris Sakakushev, Krasimira Georgieva. Study of the applicability of photogrammetric method for measuring very small size, Proceedings Mechanics, Mechanical and Manufacturing Engineering, 2015, issue 54, p.2, pp. 15-19, ISSN 1311 3321.

IRTIIE Vol. 4, No. 4, 2016 ISSN 1314-8788 (print), ISSN 1314-8796 (online), doi: 10.15547/artte.2016.04.005 


\section{ARTIE \\ ( \\ Ipplied Researl'hes in Technics, Technologies ind Bductition \\ Journal of the Faculty of Technics and Technologies, Trakia University https://sites.google.com/a/trakia-uni.bg/artte/}

[3] Karamanov A.G. Photogrammetry, Saint Petersburg national research university of informatics, technologies, mechanics and optic, Saint Petersburg, 2012, pp.171, e-book, http://open.ifmo.ru/.

[4] Kurantov A. P., Stiagkin N. I. 1978. Occam. „Misl”, Moskva, 1978.

[5] Sakakushev B., V. Grigorov, G. Georgiev. Methodology for determining the distance to an object using a stereo photogrammetry, International scientific conference - Theoretical and practical aspects of the development of modern science, VIII International scientific and practical conference, Moskva, 29 June 2013 Scientific Information publishing center «Institute for Strategic Studies». - Moskva: publishing center «Spetskniga», 2013, ISBN 978-5-91891-297-3, pp. 77-80.

[6] Bryman Alan. Triangulation, Encyclopedia of Social Science Research Methods, SAGE Publications, 08.11.2011, http://www.referenceworld.com.

[7] Georgiev Georgi \& Georgieva Nely. Investigation possibilities for the use of free software for data processing used for accurate measurement details through photogrammetry, ARTTE Vol. 2, No. 3, 2014 ISSN 1314-8788 (print), ISSN 1314-8796 (online), pp. 202210.

[8] Georgiev Georgi, Nely Georgieva, Vesislava Dimitrova. Exploring the possibilities of using the reverse engineering to recreating digital model of a geometrical object with insufficient information, ARTTE Vol. 3, No. 4, 2015 ISSN 1314-8788 (print), ISSN 13148796 (online), pp. 258-265.

[9] Yankov K. (2010) Preprocessing of Experimental Data in Korelia Software. Trakia Journal of Sciences. 2010; Vol. 8, Suppl. 3, pp. 41-48. 